\title{
Association of Food Intake Patterns and Parents' Educational Levels with Nutritional Statuses of School-Going Children (5-13 years old) in Rural Areas of Northern Bangladesh
}

\author{
Ashikur Rahman ${ }^{12 *}$ Muhammad Ayb ${ }^{2}$, Ariful Ahsan ${ }^{2}$ \\ 1-Food Safety and Quality Analysis Division,Institute of Food and Radiation Biology, Bangladesh Atomic Energy Commission, Bangladesh \\ 2-Department of Food Technology and Nutritional Science, Mawlana Bhasani Science and Technology University, Tangail, Bangladesh
}

\section{A B S T R A C T}

Background and Objectives: Children malnutrition is a serious problem worldwide, especially in developing countries. The present study designed to investigate nutritional statuses and their associated risk factors in school-going children in Bangladesh.

Materials and Methods: This study included 650 children (391 boys and 249 girls) aged 5-13 years old, living in the rural area of northern Bangladesh. Anthropometric measurement was carried out to measure the nutritional statuses of the participants. The participants were asked for their dietary history. Food frequency questionnaire was used to collect dietary intake information. All participants were interviewed about their personal characteristics and health conditions. All information were recorded in questionnaires.

Results: Result of the study raveled that nutritional status of $37.53 \%$ of the participants were good and the rest were malnourished. Results demonstrated dominant underweight (boys, $50.38 \%$ and girls, $63.85 \%$ ), wasting (42.19\% of boys and $67.46 \%$ of girls) and stunting (boys, $47.05 \%$ girls, $77.51 \%$.) within the participants. Furthermore, study raveled that educational levels of the parents were low that might affect dietary intakes of the children and result in high prevalence of malnutrition in the studied area.

Conclusions: It is concluded that the parents' educational levels were highly important for the nutritional statuses of the children. Girls were more malnourished than boys in this study. This study have suggested further assessment of the socioeconomic statuses of the households in relation to children malnutrition.

Keywords: Children, Education, Nutrition, Malnutrition, Underweight, Stunting, Wasting

\section{Introduction}

Nutritional statuses of children increase worldwide concerns within rapid economic growths and social changes. Nutritional statuses of childhood determine health statuses of adult and elderly people (1). Intermittent growth checking is a significant marker of the health and nutritional status of children (2). Overconsumption of calories or inadequate intakes of one or more nutrients may lead to imbalance nutrition and can be a threat for health. Balanced diets are essential for the fundamental body functions and proper brain developments (3). The primary school age is considered as an active phase of physical and mental development of the children. Malnutrition of primary-school-age children may lead to low school enrolment, excessive absence, quick dropout and poor classroom performance (4). Insufficient intake of foods decreases cognitive power, school functioning, growth retardation, physical activities and resistance infections and increases morbidity and mortality rates as consequences of increased adverse effects on productivity, income and national development. In developing countries, various factors linked to malnutrition of school-going children such as low economic statuses, poor knowledges about quantity and quality of diets and insufficient health and nutrition services (5).

Defective feeding patterns, sex discriminations, big family sizes and ignorance of the family are causal reasons for the children malnutrition (6). It is estimated that more than 200 million school-going children are affected. If the 
necessary initiatives are delayed, approximately 1 billion stunned school-going children are rising up by 2020 with destabilized physical and mental health statutes (7). In 2010, Food and Agriculture Organization (FAO) reported that the proportion of malnutrition in Bangladesh was the highest in the world. This report stated that more than $54 \%$ of preschool-age children (9.5 million children) were stunted, $56 \%$ were underweighted and more than $17 \%$ were wasted. Although the entire administrative divisions in Bangladesh were concerned about children malnutrition, there were significant differences in prevalence of the three anthropometric indicators. Dominance of underweight ranged from $49.8 \%$ in Khulna to $64.0 \%$ in Sylhet, which also presented the highest dominance of stunting $(61.4 \%)$ and wasting $(20.9 \%)$ (8). Despite the extreme stages, the rate of stunting has decreased gradually within the last ten years (8). The present study aimed to assess the nutritional status of the school-age children in a rural area of northern Bangladesh and investigate its associate factors to prevent future childhood malnutrition.

\section{Materials and Methods}

This study was a cross-sectional study, assessing nutritional statuses and associated factors that affected growth and mental development of school-going children aged 5-13 years old. The study was carried out at Pabna District under Rajshahi Administrative Division in Bangladesh. Totally, 12 schools were selected using random procedures for data collection. The sample size included 6325 and $11.5 \%$ of the sample size was 650 ; of which, 391 were boys and 249 were girls aged 5-13 years old from a rural area of northern Bangladesh. Inclusion criteria for boys and girls included aging between 5 and 13 years old, being student of the primary school and willing to participate in this study. Subjects who were not qualified were excluded from the study. Physical characteristics such as body weight and height of the children were used to measure the nutritional statuses of the participants. Depending on the age, body weight and height of the participants, various indicators of height-for-age and weight-for-height and weight-for-age were established to assess the nutritional status [9]. Standard weighing scale was used to measure weight of the children. Children stood on the surface of the weight scales, wearing light clothes with no shoes. Weight was noted to the closest value of 0.1 $\mathrm{kg}$. Height was measured using measuring tape. Height was measured to the closest value of $\mathrm{cm}$. Underweight was calculated based on World Health Organization/National Center for Health Statistics (WHO/NCHS) classification of low weight for age (10). Stunting of the children was measured using a formula by WHO/NCHS as low heightfor-age (11). Wasting of the participants was assessed using classification of WHO/NCHS as low weight-forheight (12). Body mass index of the participants was measured using the formula of BMI = Body weight $(\mathrm{kg}) /$ body height $(\mathrm{m})^{2}$. The participants were asked for their dietary history. Nutritional intakes of the participants were recorded in food frequency questionnaires (FFQ). Food frequency questionnaires included rice, bread, meat, fish, egg, milk, pulses (dhal), fruit and vegetable mainly consumed by Bangladeshi people. Well-developed questionnaires, excluding economic conditions due to their confidential purposes and including personal information, parents' educations and dietary frequencies were used to collect data through face-to-face interviews with the participants and their parents.

Statistical analysis: Data presented in this study expressed as percentages. Independent sample t-test was used to compare malnutrition between the boys and the girls. Data analysis was carried out using Macintosh SPSS software v.19.0. Microsoft Excel was used for graph preparation.

\section{Results}

Table 1 shows that children aged 9-10 years old more participated in this study (39.23\%), compared to other age groups. The study participants included $60.15 \%$ of boys and $39.85 \%$ of girls because more boys were comfort to participate in this study.

The highest number of the participant were Muslim $(87.69 \%)$ in this study, compared to other religions due to nearly $93 \%$ of resident Muslims in Bangladesh.

Table 1. Demographic data of the children

\begin{tabular}{llcc}
\hline Variable & & $\begin{array}{c}\text { Frequency } \\
\text { (n) }\end{array}$ & $\begin{array}{c}\text { Percentage } \\
(\%)\end{array}$ \\
\hline Age & 5 to 8 years old & 195 & 30.00 \\
& 9 to 10 years old & 255 & 39.23 \\
& 11 to 13 years old & 200 & 30.77 \\
Sex & & & \\
& Boy & 391 & 60.15 \\
\multirow{5}{*}{ Religion } & Girl & 249 & 39.85 \\
& Muslim & 570 & 87.69 \\
& Hindu & 47 & 7.23 \\
& Others & 33 & 5.08 \\
\hline
\end{tabular}

Education levels of the parents played a key role in child health. A majority of the parents were illiterates in this study. Minimum numbers of $14.46 \%$ and $10.30 \%$ of fathers and mothers respectively were graduates and the rest of the parents had average educational levels (Table 2). Fathers and mothers of $29.23 \%$ and $26.61 \%$ of the participants had primary educations, respectively. Maximum numbers of $31.54 \%$ of fathers and $28.79 \%$ of mothers were found illiterates. 
Table 2. Educational levels of the participants' parents

\begin{tabular}{lcccc}
\hline Education level & \multicolumn{2}{c}{ Frequency(n) } & \multicolumn{2}{c}{ Percentage $(\%)$} \\
\cline { 2 - 5 } & Father & Mother & Father & Mother \\
\hline Graduate & 94 & 67 & 14.46 & 10.30 \\
Higher secondar & 105 & 94 & 16.15 & 14.46 \\
Secondar & 156 & 129 & 24.00 & 19.85 \\
Primary & 190 & 173 & 29.23 & 26.61 \\
Illiterate & 205 & 187 & 31.54 & 28.79 \\
\hline
\end{tabular}

Balanced diets are essential for better nutritional statuses in children. Most of the participants were deprived of the balanced diet (Figure 1). All participants consumed rice regularly. Most participants of $37.38 \%$ and $55.07 \%$ consumed vegetables and fruits weekly and fortnightly, respectively. Egg, meat, fish, milk and rice are sources of proteins and fats. Figure 1 demonstrates that participants consumed low quantities of proteins and fat-rich foods. Maximum numbers of participants of $72 \%, 47.38 \%$, $45.53 \%$ and $54 \%$ consumed meat, milk, egg, and fish fortnightly. Participants of $1.07 \%, 15.7 \%, 13.2 \%$ and $10.65 \%$ consumed meat, fish, milk and egg regularly.

Based on the BMI, $37.53 \%$ of the participants were well-nourished and $62.47 \%$ were malnourished (Table 3 ). The BMI of 18.50-24.99 was considered as wellnourished. The maximum number of participants $(55.99 \%)$ were mild and moderate malnourished. Mild and moderate malnourishes were classified based on the BMI of 17.00 18.49 and 16.00-16.99, respectively. The BMI below 16 was considered as severely malnourished and $6.46 \%$ of the participants were classified in this category.

Table 3. Classification of nutritional statuses of the participants using body mass index as an indicator

\begin{tabular}{lcc}
\hline Nutritional status & Frequency(n) & Percentage $(\%)$ \\
\hline Normal & 244 & 37.53 \\
Mildly Malnourished & 176 & 27.07 \\
Moderately Malnourished & 188 & 28.92 \\
Severely Malnourished & 42 & 6.46 \\
\hline
\end{tabular}

The maximum number of well-nourished (normal) children ranging $26.01 \%-32.37 \%$ in this study had parents with secondary to graduate-level educations, respectively. Whereas, $41.13 \%$ of high malnourished children had illiterate parents (Figure 2). Figure 2 demonstrates that parents' educational levels highly affected nutritional statuses of the children. Parents were illiterate and primary educational levels had no adequate knowledge to select nutritious food and other health concerns.

Significantly ( $p=0.008$ ), girls were higher malnourished compared to boys. Figure 3 illustrates that boys were less underweight $(50.38 \%)$, wasted $(42.19 \%)$ and stunted $(47.05 \%)$ whereas girls were more underweight $(63.85 \%)$, wasted $(67.46 \%)$ and stunted $(77.51 \%)$.

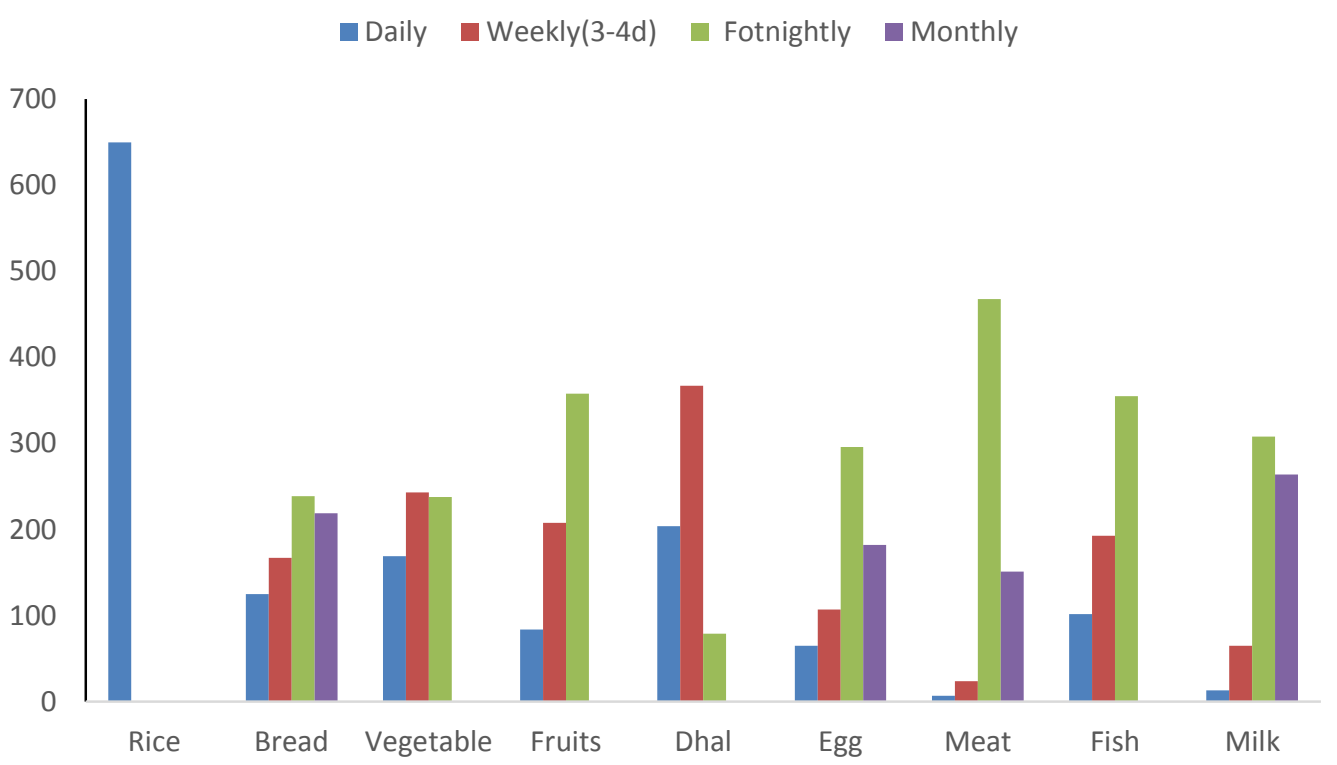

Figure 1. Food intake patterns of the participants 


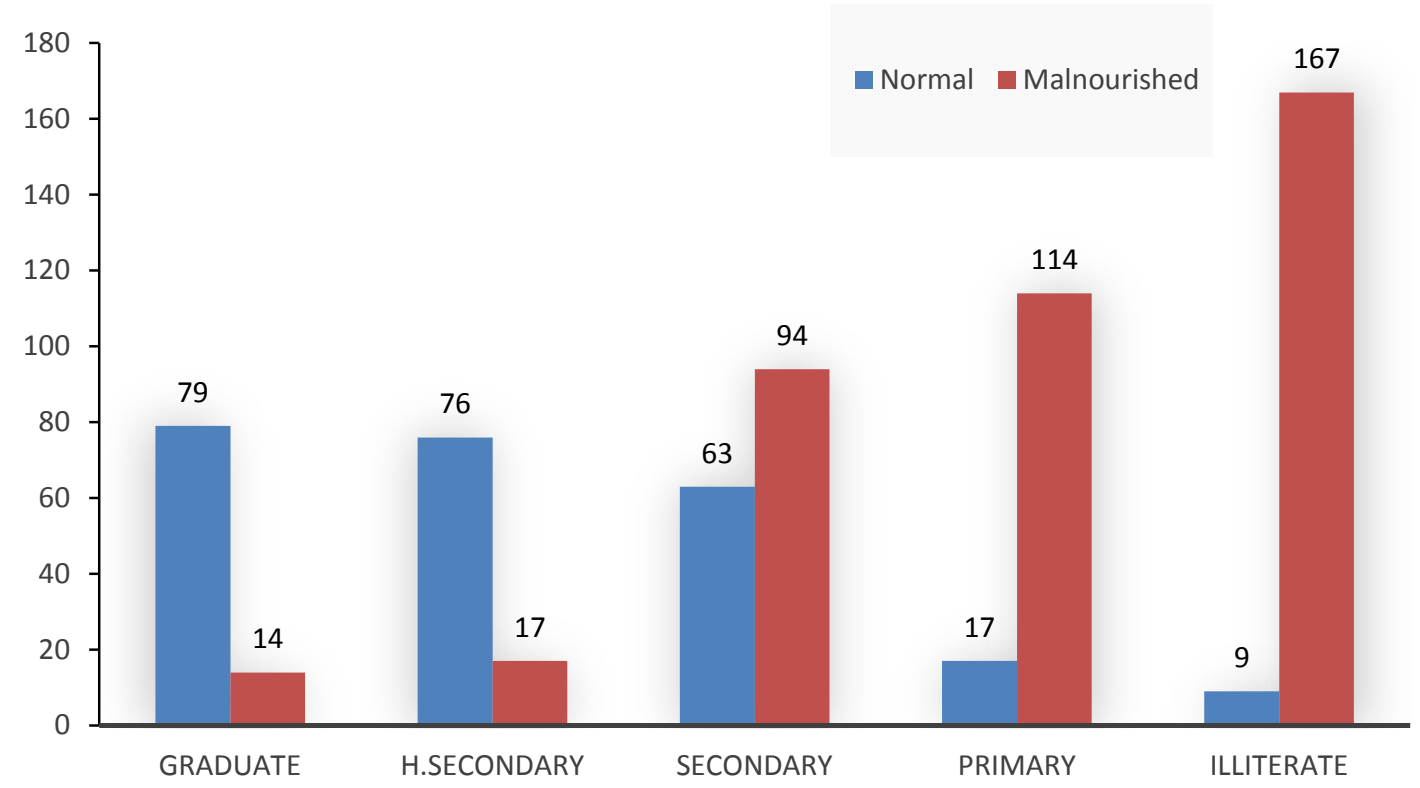

Figure 2. Relationships between the parents' educational levels and nutritional statuses of the children

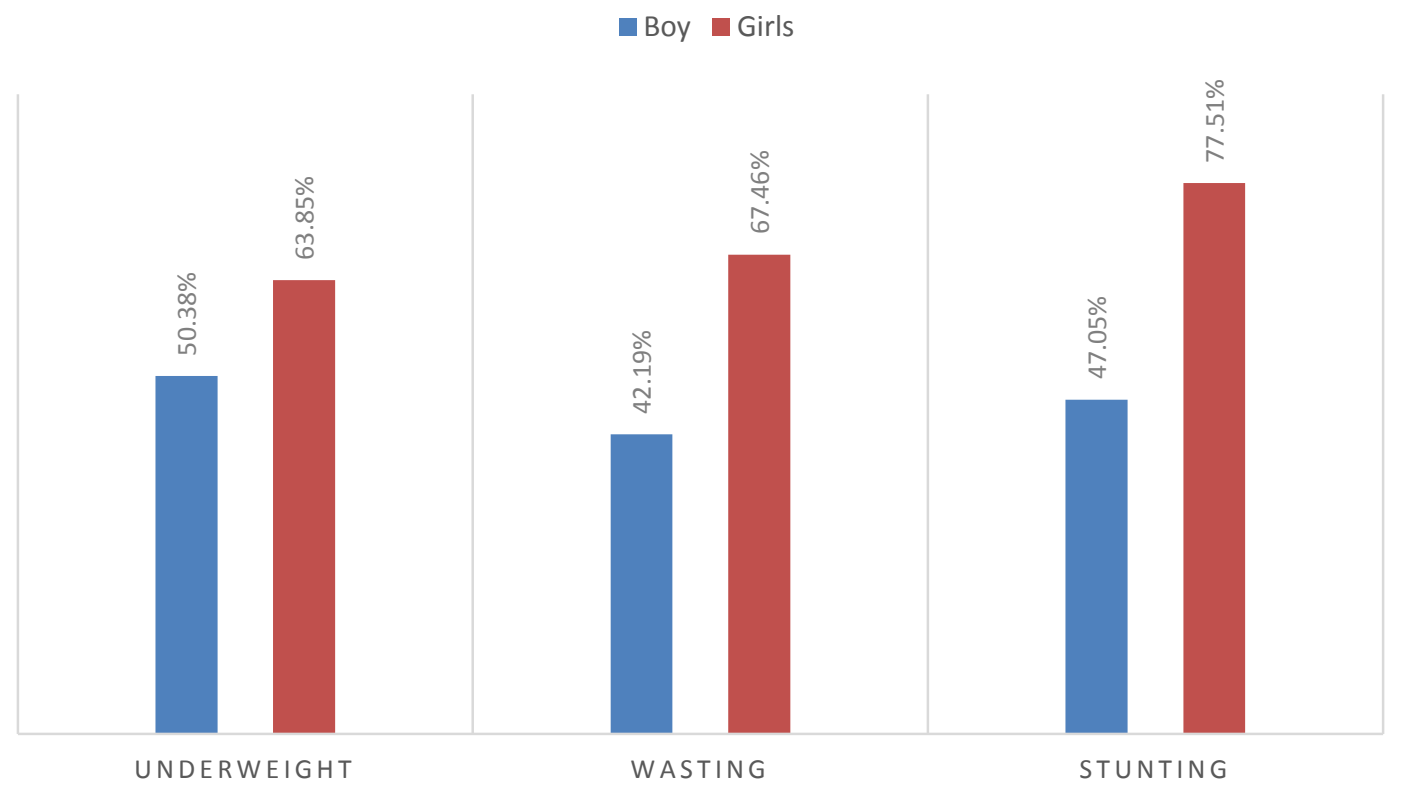

Figure 3. Comparisons of the nutritional statuses between boys and girls

\section{Discussion}

Assessment of the nutritional statuses in children is one of the first initiatives for the design of a public health scheme to fight against malnutrition. The primary objective of such an assessment is to identify nature, level and dissemination of malnourishments in distinctive geographical zones and categorize at-risk populations as well as determination of affecting factors (13). The current study illustrated nutritional statuses of the children aged over five years old from a rural area (Rajshahi Division) of northern Bangladesh. It is noteworthy that the current study might not contain nutritional statuses of the children from various age groups across the country. The school-age period is a fundamental stage of the human life. Children are highly vulnerable to malnutrition due to their age, sex, dietary intake pattern and parents' educational level (14). The present study demonstrated that $37.53 \%$ of the participants were well-nourished and the rest were malnourished; of which, $57.21 \%$ were underweight, 
$54.82 \%$ were wasted and $85.80 \%$ were stunted. Results are in contrast to a previous study in 1990 , reporting that the nutritional statuses of school-going children in Bangladesh were $26.2 \%$ normal for all parameters, $47.3 \%$ wasted and $14.3 \%$ stunted (15). Another study in 1990 reported that $51 \%$ of the children were normal, $15 \%$ were stunted and $32 \%$ were wasted (16).

Dietary intake patterns in this study were highly linked to malnourished children. Rice and bread provided carbohydrates. Fruits and vegetables provided essential nutrients such as vitamins, minerals and antioxidants. Food intake patterns of the participants demonstrated that malnutrition children from illiterate and primary educated families were more malnourished than other children because of their inadequate nutritious food intakes. Illiterate people are unconcerned of links between food and health. Low educated parents do not have sufficient knowledge about the nutritional values of foods and balance diets that badly affect growth and mental developments of their children. Lack of knowledge about the locally accessible nutritious foods may affect nutritional statuses of the children, increasing malnutrition. Results of this study are similar to those from previous studies reporting that educated parents (majorly mothers) are important to effectively practice nourishing their children with balanced diets. Ordinary, parents are responsible for buying and cooking foods at homes that may affect food preferences of their children $(17,18)$.

\section{Conclusion}

Results of this study raveled that girls were more malnourished than boys. Undernutrition is a wide-spread problem that may reveal high dominance of underweight, stunting and wasting in children. Parents' educational levels and dietary intake patterns directly affect insufficient consumptions of proteins and fat-rich foods that may lead to failure of mental and body growth. This study has suggested that education of parents helps balanced diets to eliminate malnutrition.

\section{Acknowledgement}

The authors would like to express their gratitude to the participants and their parents. The authors would like to thank volunteers for their cooperation during data collection.

\section{Financial disclosure}

The authors declare no conflict of interest.

\section{Funding/Support}

The authors did not receive any founds for this study.

\section{References}

1. Fazili A, Mir A, Pandit IM et al. Nutritional Status of School-Age Children (5-14 years) in a Rural Health Block of
North India (Kashmir) Using WHO Z-Score System. Online Journal of Health and Allied Sciences. 2012; 11:1-3.

2. De Onis M, Bl.ssner M: The World Health Organization Global Database on Child Growth and Malnutrition: methodology and applications. Int J Epidemiol. 2003; 32(4): 518-526.

3. Onis MD, Monteiro C, Akre J, Clugston G. The worldwide magnitude of protein-energy malnutrition: an overview from the WHO global database on child growth. Bull World Health Organ. 1993;71:703-12.

4. International Institute of Population Sciences (IIPS) National Family Health Survey (NFHS-3), Fact sheets for 29 States. Mumbai: International Institute for Population Sciences India, Mumbai 2007.

5. Kurz KM, Johnson-Welch C. The nutrition and lives of girls in developing countries: findings from the nutrition of adolescent girl's research program. Washington, DC: International Center for Research on Women; 1994.

6. The World Bank. Undernourished. Chapter 1. Available from: www.worldbank.org.

7. UNICEF. Levels and Trends in Child Mortality. Estimates Developed by the UN Inter-Agency Group for Child Mortality Estimation (2011).

8. Food and Agriculture Organization (FAO). Nutrition Country profiles: Bangladesh Summary: fao.org/ag/agn/nutrition/bgd_en.stm.: Access 2010

9. Waterlow IC, Buzina R, Keller W, Lane IM, Nichaman MZ, Tanner IM: The presentation and use of height and weight data for comparing the nutritional status of groups of children under the age of 10 years. Bull World Health Organ 1977, 55:489-498.

10. Jelliffe DB. The Assessment of the Nutritional Status of the Community. WHO Monograph Series No. 56, WHO, Geneva (1966).

11. Waterlow JC (Introduction. Causes and mechanism of the growth retardation (stunting). Eur J Clin Nutr 48 Supple 1977; 1: S1-S4.

12. Waterlow JC. Classification and definition of protein calories malnutrition. Bri Med Gaz 1972; 3:566-569.

13. Allen LH \& Gillespie SR.What works? A review of the efficiency and effectiveness of nutrition interventions. United Nations. Administrative Committee on Coordination/ SubCommittee on nutrition, Geneva. Asian Development Bank, Malina, ACC/SCN Nutrition Policy Paper No. 9. ADB nutrition and development series, Geneva 2001;5:24-25.

14. Park's Text Book of Preventive and Social Medicine 16th Ed. 2001.

15. Ahmed, R.Kabirullah, M. Shahjahan, M. Nessa, Z. Miah, S. Khan, S. A.Nutritional status of school-going children in Bangladesh, DS (child) H J.1990; 6(1):13 
16. Karim R.Bhuyan, M. A. H. and Sukanta, S. Nutritional status of children in an urban primary school in Dhaka. Bangladesh Journal of Nutrition, 1990); 4(1): 53- 61.

17. Nicklas T, Hayes D. Position of the American Dietetic Association: nutrition guidance for healthy children ages 2 to 11 years. J Am Diet Assoc. 2008;108(6):1038-44.
18. Chong KH, Lee ST, Ng SA, Khouw I, Poh BK. Fruit and Vegetable Intake Patterns and Their Associations with Sociodemographic Characteristics, Anthropometric Status and Nutrient Intake Profiles among Malaysian Children Aged 1-6 Years. Nutrients. 2017;9(8):723. 